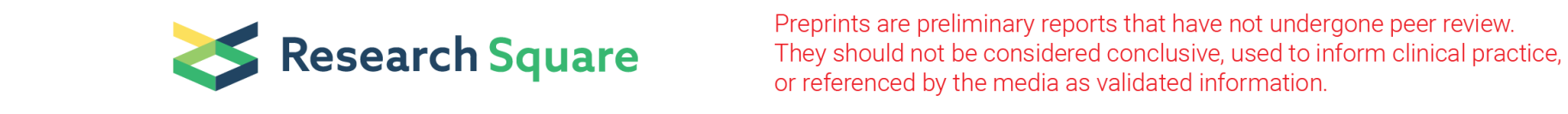

\title{
Novel Metabolites Identified From Bacillus Safensis and Their Antifungal Property Against Alternaria Alternata
}

Jai Prakash

Laboratory for Rhizosphere Microbiology and Sustainable Agriculture (LRMSA), 1Department of Environmental

Microbiology (DEM),

Naveen Arora ( $\sim$ nkarora.bbau@gmail.com)

Babasaheb Bhimrao Ambedkar University https://orcid.org/0000-0001-9412-663X

\section{Research Article}

Keywords: Bacillus safensis, Alternaria alternata, biocontrol, metabolites, antifungal organic volatile compounds

Posted Date: February 22nd, 2021

DOI: https://doi.org/10.21203/rs.3.rs-214500/v1

License: (c) (i) This work is licensed under a Creative Commons Attribution 4.0 International License. Read Full License 


\section{Abstract}

Plant growth promoting rhizobacteria offer an effective and eco-sustainable solution to protect crops against phytopathogens. In the present study, Bacillus safensis STJP (NAIMCC-B-02323) from the rhizospheric soil of Stevia rebaudiana showed strong biocontrol activity against phytopathogen, Alternaria alternata. B. safensis STJP produced antifungal volatile organic compounds (AVOC). In the presence of AVOC, there was no conidia germination, mycelium growth was inhibited, and hyphae ruptured as observed by scanning electron microscopy (SEM). When mycelium of the fungus from bacterial treated plate was transferred into fresh potato dextrose agar plate, A. alternata could not grow. Extracted AVOC from B. safensis STJP were identified by thin-layer chromatography (TLC), fourier-transform-infrared spectroscopy (FT-IR) and gas-chromatography-mass spectrometry (GC-MS). In total 25 antifungal metabolites were identified by GC-MS analysis having alcohol, alkane, phenol, alkyl halide and aromatic compounds. Five compounds (phenol, 2,4-bis (1,1-dimethylethyl)-, 3-hexadecanol, pyrrolo(1,2-a)pyrazine-1,4-dione, 5,10-diethoxy-2,3,7,8-tetrahydro-1H,6Hdipyrrolo(1,2-a:1',2'-d)pyrazine and hexadecanoic acid) completely inhibited the mycelium growth, controlling spore formation and conidia germination of $A$. alternata. This study concluded that AVOC producing $B$. safensis can be used as a green-fungicide against $A$. alternata. Bacterial metabolites could pave the way for the development of next generation biopesticide. This can be a reliable technology to enhance the quality and reliability of biopesticides.

\section{Introduction}

According to estimates, the world population is expected to reach 9 billion by 2050 (FAO 2012). Hence, the demand for food is rising continuously so as to feed the ever growing population. Currently, the total cost of annual food production is USD 1300 billion, out of which 500 billion is lost every year due to biotic stresses such as weeds, insects, fungus, virus and bacterial diseases (Watts et al. 2018). Among all, phytopathogens (including bacteria and fungi) account for yearly loss of USD 120 billion during crop production and after harvesting (Shuping et al. 2017). Decrease in the crop yields and impact on economy due to phytopathogens are often more severe in developing and poor countries, particularly where economy largely depends on agriculture (Danial et al. 2020).

Deadly fungal phytopathogen Alternaria spp. is commonly responsible for the reduction of crop productivity all around the globe (Chakraborty and Newton 2011; Müller, et al. 2019). It is one of the common fungal genus, reported around the globe with endophytic, saprophytic and pathogenic properties and also responsible for reduction in crop productivity (Müller, et al. 2019). Alternaria spp. are opportunistic pathogens, causing widespread damage to a number of crops and results in up to $80 \%$ reduction of yield in affected fields (Nowicki et al. 2012). A. alternata is known to cause leaf spot disease in several crops including Stevia rebaudiana (Meena et al. 2017). The leaf spot disease is identified by the presence of dark brown color or necrotic lesions on the leaf (Danial et al. 2020). The symptoms of this disease appear after infection and during pathogenesis, when fungal metabolites impact the plant during active phase of growth (Thomma 2003). The spores of $A$. alternata are dispersed ubiquitously and can spoil cereals, grains, fruits, foods and damage vegetative parts of the plants and ultimately decrease their nutritive value by secretion of several toxic metabolites (Meena et al. 2017).

Crop rotation, cultural practices, or use of disease-resistant varieties are commonly employed for the management of soil borne pathogens (Roy et al. 2018), but these methods are not satisfactory for control of phytopathogens. Although, chemical pesticides are efficient way to control fungal pathogens and enhance crop productivity, but their application is being increasingly limited or banned due to negative impact on the soil fertility, microbial diversity, and ecosystem and causes toxicity to animals and humans (Alori and Babalola 2018; Prakash, and Arora, 2019). Beside these, green house emission and environmental pollution are also caused due to production and application of pesticides (Harman and Uphoff 2019). Hence, this situation calls for management strategies. Biopesticides are being used to control fungal diseases along with enhancing crop yields in an eco-friendly manner. Microorganisms with the abilities of biocontrol of phytopathogens are being used as biopesticides to realize the target of sustainable agriculture (Mishra et al. 2016). Low input biotechnology utilizing biocontrol agents for suppression of diseases and increased plant growth has now become a needful sector for

Page 2/17 
research so as to obtain quality products which are reliable and equal or even more effective than chemical pesticides (Shumaila and Khan 2016).

Gram-positive Bacillus spp. are one of the front runners for use as biopesticides because of their ability to produce a number of secondary metabolites with very different structure and nature and also broad spectrum antifungal potential (Kapetanakou and Skandamis 2016; Kai 2020). Rhizospheric Bacillus spp. are widely known to produce secondary metabolites such as bacitracin, polymyxins, lipopeptide surfactin, subtilosin, lantibiotic, iturin and gramicidin (Stoica et al. 2019; Kaspar et al. 2019). There is a continuous need to extract and identify biocontrol metabolites to develop biopesticides with effective potential against fungal pathogens such as $A$. alternata. The objective of the present study was to investigate the biocontrol potential of $B$. safensis strain against $A$. alternata. Extracellular antifungal metabolites produced by $B$. safensis were identified and checked for inhibition of $A$. alternata so as to check the mechanism of biocontrol agent (BCA) and determine the effective anti-fungal biochemicals.

\section{Materials And Methods \\ 2.1. Microorganisms}

B. safensis STJP NAIMCC-B-02323 taken for the study has already been reported as an effective plant growth promoting rhizobacteria (PGPR) (Prakash and Arora 2019; Prakash and Arora 2020). B. safensis STJP showed plant growth promoting (PGP) characters viz. solubilization of phosphate, zinc, potassium, production of siderophore, and indole acetic acid (IAA) as reported in earlier studies by the authors (Prakash and Arora 2019; Prakash and Arora 2020). A. alternata isolate P1 (accession number: KX494864) was procured from Laboratory for Rhizospheric Microbiology and Sustainable Agriculture, School for Environmental Science, Babasaheb Bhimrao Ambedkar University, Lucknow and grown (at $28^{\circ} \mathrm{C}$ ) and maintained on potato dextrose agar (PDA) and Czapex dox agar (CDA) at $4{ }^{\circ} \mathrm{C}$ for further use and experiments. The fungal isolate has also been already reported as a phytopathogen in an earlier study (Prakash and Arora 2019).

\subsection{Rapid screening technique}

A rapid screening test is a simple process, done in the laboratory on the Petri plate for screening of antagonistic microorganisms. For rapid screening test, fungal mycelia and hyphae were cut with the help of cork borer (from an already cultured PDA plate and kept in the centre of prepared PDA plate and STJP was spotted and streaked (on separate plates) around the fungal pathogen (Schoeman et al. 1994). Subsequently, Petri plate were incubated for $120 \mathrm{~h}$ at $28^{\circ} \mathrm{C}$ and calculated for fungal growth inhibition rate as per Schoeman et al. (1994).

\subsection{Dual culture method}

Dual culture test was performed on PDA (Himedia, Mumbai) for screening of biocontrol potential as per Arora et al. (2001). Briefly, the fungal mycelium was cut $(5 \mathrm{~mm}$ ) by cork borer (from a PDA plate grown with $A$. alternata after 5 days incubation period) and placed on the center of PDA plate. Afterwards, the fresh log phase culture of B. safensis STJP (on the basis of rapid screening) was streaked on two edges of Petri plate (Arora et al. 2001). Further, Petri plates were sealed with parafilm and then incubated at $28^{\circ} \mathrm{C}$ for $120 \mathrm{~h}$. After incubation period, the inhibition of fungal growth was observed and inhibition zone was calculated by using the formula: $100 \times(\mathrm{C}-\mathrm{B}) / \mathrm{C}$; where; $\mathrm{C}$ is the diameter of fungal colony in control plate and $\mathrm{B}$ diameter of fungus in the dual culture plate.

\subsection{Screening of bacteria for antifungal volatile compound production by seal plate method}

Bacterial strain $B$. safensis STJP was checked for the production of antifungal volatile compounds as per Fernando et al. (2005). Actively growing mycelia (disc) of $A$. alternata $(5 \mathrm{~mm})$ were kept at the center of Petri plate containing PDA. The overnight grown bacterial culture was spread on another Petri plate containing nutrient agar (NA). Petri dish containing 
fungal mycelia was inverted over the NA and both plates were immediately wrapped with parafilm. The plates were further

incubated for $120 \mathrm{~h}$ at $28^{\circ} \mathrm{C}$. Every $24 \mathrm{~h}$, growth inhibition of $A$. alternata by bacterial isolate was observed in comparison to control plate (contained only mycelia) as per Fernando et al. (Kersten and Kirk 1987). After 120 h, fungal mycelia were detached from the plate and further confirmed for viability in a fresh Petri plate containing PDA. The experiments were repeated three times with five replicates taken each time.

\subsection{Growth inhibition of $A$. alternata by extracellular or intracellular metabolites}

The overnight grown bacterial culture was inoculated in nutrient broth and incubated $\left(28^{\circ} \mathrm{C}, 48 \mathrm{~h}\right)$. After incubation, broth was centrifuged at 5,000 rpm for $15 \mathrm{~min}$ to get the supernatant and pellet. Subsequently, two wells were made on the prepared PDA plate with the help of sterilized cork borer and the obtained supernatant and pellet were transferred in the well of Petri plate (separately), with A. alternata at centre point to check whether the biocontrol activity is by extracellular or intracellular metabolites (Kersten and Kirk 1987). Besides, control plate of $A$. alternata was also incubated simultaneously. All the plates were incubated for $120 \mathrm{~h}$ at $28^{\circ} \mathrm{C}$.

\subsection{Growth inhibition of $A$. alternata checked by scanning electron microscopy}

For sample preparation of scanning electron microscopy (SEM), the fungal mycelia were picked up from dual culture and control plates and fixed with modified Karnovsky's fixative ( $2 \%$ glutaraldehyde and $2 \%$ paraformaldehyde in sodium cacodylate buffer (0.05 M; pH 7.2) and incubated for $12 \mathrm{~h}$ at $4^{\circ} \mathrm{C}$ (Kaminskyj and Dahms 2008). Further, the fixed specimen sample was washed three times with sodium cacodylate buffer $(0.05 \mathrm{M})$ for $12 \mathrm{~min}$ followed by washing with distilled water. Subsequently, dehydration was done of the specimen with an ethanol solution of concentration of $30 \%, 50 \%, 70 \%$, $80 \%$, and $90 \%$ (5 min), and lastly, absolute (100\%) ethanol was used (three times) for dehydration of cell for 2 min (Hennequin et al. 2006). Afterwards, the specimen was further dried by using hexamethyldisilazane and with the help of a sputter coater, and specimen was finally coated with gold (MSC-101, JOEL). The prepared sample of the specimen was observed under SEM (Model: JSM-7610F, JEOL, Japan).

\subsection{Extraction and purification of metabolites}

For extraction of antifungal metabolites, $24 \mathrm{~h}$ culture of bacterium STJP (selected on the basis of PGP traits) was inoculated in NB and inoculated at 120rpm, $28^{\circ} \mathrm{C}, 7$ days (Model: Labtech LS1-3016R). After the incubation period, the broth was centrifuged (rpm: 10,000rpm, $15 \mathrm{~min}, 4^{\circ} \mathrm{C}$ ) (Centrifuge Model: Sigma 3-18KS) to obtain supernatant. The pH of the obtained supernatant was adjusted at 7.0 and subsequently it was dissolved in the solvent; chloroform + ethyl acetate + dichloromethane (DCM) in a ratio of 1:2:1 as per Hennequin et al. (Hennequin et al. 2006). Further, 50 ml of solventsupernatant mixture was filled in a separating funnel and mixed vigorously for $15 \mathrm{~min}$. The funnel was then hanged on a stand and this process was done for $24 \mathrm{~h}$ at $28^{\circ} \mathrm{C}$. The transparent layer of the reaction mixture containing metabolites was removed from the separating funnel and the sample was filtered via Whatman number 42 containing $5 \mathrm{gm}$ of sodium sulphate (anhydrous compound, HiMedia, Mumbai) as per Hennequin et al. (2006). The obtained sample containing antifungal metabolites was kept in a sterilized beaker, and finally, solvent was evaporated by using a rotatory vacuum evaporator (Model: UTS: 1.53, Thermo-scientific).

\subsection{Thin Layer Chromatography (TLC)}

Thin layer chromatography (TLC) was done for the separation of different compounds present in the crude metabolite sample as per Reddy et al. (Reddy et al. 2009). Briefly, TLC was done on freshly prepared silica plate $(20 \mathrm{~cm}$ long x $10 \mathrm{~cm}$ width) by using mobile phase [chloroform: methanol (80:20)]. The crude metabolite $(10 \mu \mathrm{g})$ was spotted on the silica plate and the solvent was allowed to run from bottom to top. The retardation factor (RF) value was calculated as per Reddy et al. (2009). The running lane was then dried thoroughly and the fraction of the compound was analyzed under UV light 
$(254 \mathrm{~nm})$. Different bands of metabolites were scraped separately into microcentrifuge tubes and further centrifuged with ethyl acetate as per Gocan (2002). After centrifugation, the solvent was evaporated through a rotatory vacuum evaporator (Model: UTS: 1.53, Thermo-scientific) and finally supernatant was taken for further experiment.

\subsection{Fourier Transform Infrared Spectroscopy (FT-IR)}

To analyze the functional groups of purified metabolites of bacterium STJP (obtained after TLC), the sample was dried in a hot air oven at $40^{\circ} \mathrm{C}$ and subsequently analyzed as per Reddy et al. (2009). Briefly, the dried sample of metabolites was mixed with analytical grade potassium bromide ( $\mathrm{KBr}$ ) (IR Grade; purity $\geq 99 \%$ ) (1:30 ratio) and the reaction mixture was thinly ground and further fused into a thin pellet $(13 \mathrm{~mm} \mathrm{X} 1 \mathrm{~mm})$ by $\mathrm{PCl}$ hydraulic pressure with a 15 tons capacity under vacuum pressure. Afterwards, spectra absorbance was observed by FT-IR (Model: Nicolet ${ }^{\mathrm{TM}}$ 6700, Thermo Fisher Scientific, USA). Further, the result was analyzed in the mid-infrared region from 4000 to $450 \mathrm{~cm}^{-1}$ with a resolution of $4 \mathrm{~cm}^{-1}$. For spectrum peak, scanning was done and the pure $\mathrm{KBr}$ as a background spectrum was kept to measure in the ambient air. The processing of data was done using $\mathrm{OMNIC}^{\mathrm{TM}}$ (v7.4) software.

\subsection{Gas Chromatography-Mass Spectrophotometry (GC-MS)}

GC-MS was performed using a flame ionization detector (Model: Varian Star 3400 CX, OH, USA). Briefly, 15 m DB-1 megabore column of $100 \%$ dimethylpolysiloxane was used for the separation of the crude metabolite sample (Gocan 2002). The sample was injected into a fused silica column $\left[\left(25 \mathrm{~m} \times 0.22 \mathrm{~mm} \times 0.25 \mu \mathrm{m}\right.\right.$ (length $\mathrm{x}$ width $\mathrm{x}$ thickness)] at $22^{\circ} \mathrm{C}$ which was focused cryogenically with chilled acetone (time: $2 \mathrm{~min}$ ). This column was previously joined with a HewlettPackard 5890 gas chromatograph, linked with a selective Hewlett-Packard mass detector. For the carrier gas, helium was used and the flow rate was adjusted at $1 \mathrm{ml} / \mathrm{min}$. The temperature of GC-column was from $35-200^{\circ} \mathrm{C}$ at $4^{\circ} \mathrm{C} / \mathrm{min}$ ramp rate. The result obtained in the form of unknown compounds were compared with mass spectra (MS) using NIST/EPA/NIH mass spectroscopy library (Version 17).

\subsection{Examination of antifungal activity of volatile organic compounds}

The metabolites produced by $B$. safensis STJP and detected through GC-MS analysis were purchased (mentioned in Table 3) from Sigma Aldrich, USA (synthetic chemicals) to antifungal activities against phytopathogen ( $A$. alternata) and individually evaluated using seal plate method (Fernando et al. 2005). Briefly, a pure individual compound (purchased) with volume of $100 \mu \mathrm{l}$ was prepared and spread onto sealed Petri plate in one compartment and a $5 \mathrm{~mm}$ mycelium disk of $A$. alternata was placed in another compartment. Afterwards, plates were incubated for 5 days at $28^{\circ} \mathrm{C}$ for observation of result. For control, dimethyl sulfoxide (DMSO) was used as per Fernando et al. (2005). 
Table 1

FT-IR spectral data of bacterial metabolites with their corresponding peak assignments

\begin{tabular}{|lll|}
\hline Frequencies observed $\mathbf{( c m}-\mathbf{1})$ & Tentative peak assignments & Tentative functional groups \\
\hline 3610.0 & O-H stretching & Alcohol, phenol, carboxylic acid \\
\hline 3555.4 & O-H stretching & Alcoholic group \\
\hline 3406.5 & O-H stretching & Alcoholic and phenolic group \\
\hline 1620.8 & C-C stretching ring & Benzene \\
\hline 1434.4 & C-C stretching ring & Aromatic \\
\hline 800.7 & C-H stretching & Alkyl halide \\
\hline 662.2 & C-H stretching & Alkane \\
\hline 601.1 & -C-H stretching & Alkenes \\
\hline 465.2 & -C-Cl stretching & Alkyl halide \\
\hline
\end{tabular}


Table 2

Bacterial metabolites identified by GC-MS from extracted sample

\begin{tabular}{|c|c|c|c|c|c|c|c|}
\hline $\begin{array}{l}\text { Number } \\
\text { of Peak }\end{array}$ & $\begin{array}{l}\text { Retention } \\
\text { Time }\end{array}$ & Area & Area \% & Height & $\begin{array}{l}\text { Height } \\
\%\end{array}$ & Name of the compounds & $\begin{array}{l}\text { Base } \\
\mathrm{m} / \mathrm{z}\end{array}$ \\
\hline 1 & 21.038 & 514207 & 0.94 & 258692 & 1.35 & Nonadecane & 57.05 \\
\hline 2 & 21.439 & 15586361 & 28.42 & 6568718 & 34.28 & Phenol, 2,4-bis (1,1-dimethylethyl)- & 191.10 \\
\hline 3 & 25.191 & 982050 & 1.79 & 490797 & 2.56 & Docosane & 57.05 \\
\hline 4 & 27.006 & 222990 & 0.41 & 115581 & 0.60 & Octadecane & 57.05 \\
\hline 5 & 27.085 & 1500472 & 2.74 & 587269 & 3.06 & 3-hexadecanol & 59.05 \\
\hline 6 & 27.273 & 3044960 & 5.55 & 846893 & 4.42 & 1-proline, n-valeryl, heptadecyl ester & 70.05 \\
\hline 7 & 27.396 & 862505 & 1.57 & 363396 & 1.90 & Isopropyl tetradeconoate & 60.00 \\
\hline 8 & 27.783 & 3217193 & 6.78 & 894942 & 4.67 & $\begin{array}{l}\text { Pyrrolo[1,2-a]pyrazine-1,4-dione, } \\
\text { hexahydro-3-(2-methylpropyl)- }\end{array}$ & 70.05 \\
\hline 9 & 28.725 & 241354 & 0.44 & 102276 & 0.53 & Heptadecance & 57.05 \\
\hline 10 & 28.817 & 1742938 & 3.18 & 728708 & 3.80 & $\begin{array}{l}\text { 7,9-Di-tert-butyl-1-oxaspiro(4,5)deca- } \\
\text { 6,9-diene-2,8-dione }\end{array}$ & 57.05 \\
\hline 11 & 28.906 & 2591555 & 4.72 & 1040957 & 5.43 & Eicosane & 154.05 \\
\hline 12 & 29.374 & 7104699 & 12.95 & 1768885 & 9.23 & $\begin{array}{l}\text { 5,10-Diethoxy-2,3,7,8-tetrahydro- } \\
\text { 1H,6H-dipyrrolo[1,2-a:1',2'-d]pyrazine }\end{array}$ & 70.05 \\
\hline 13 & 29.557 & 912367 & 1.66 & 401794 & 2.10 & 3-ethyl-3-undecanol \# & 87.10 \\
\hline 14 & 29.614 & 951300 & 1.73 & 452962 & 2.36 & $\begin{array}{l}\text { 1,2-benzenedicarboxylic acid, } \\
\text { ditridecyl ester }\end{array}$ & 149.00 \\
\hline 15 & 29.765 & 3032489 & 5.53 & 992583 & 5.18 & Hexadecanoic acid & 73.05 \\
\hline 16 & 31.536 & 692718 & 1.26 & 217218 & 1.13 & Cyclohexanol, 1-butyl- & 81.10 \\
\hline 17 & 32.263 & 996868 & 1.82 & 442820 & 2.31 & Dotriacontane & 57.10 \\
\hline 18 & 32.895 & 869675 & 1.59 & 285174 & 1.49 & Tetratetracontane & 57.05 \\
\hline 19 & 33.549 & 754745 & 1.38 & 313102 & 1.63 & Hexacosyl acetate & 57.05 \\
\hline 20 & 35.898 & 270808 & 0.49 & 128222 & 0.67 & Hexatriacontane & 57.05 \\
\hline 21 & 37.239 & 850950 & 1.55 & 382659 & 2.00 & 1,3,5-Trisilacyclohexane & 130.05 \\
\hline 22 & 37.481 & 1970794 & 3.59 & 757365 & 3.95 & $\begin{array}{l}\text { d-Ribose, 2-deoxy-bis(thioheptyl)- } \\
\text { dithioacetal }\end{array}$ & 117.05 \\
\hline 23 & 37.743 & 1089259 & 1.99 & 387242 & 2.02 & $\begin{array}{l}\text { Hexadecanoic acid, 2-hydroxy-1- } \\
\text { (hydroxymethyl)ethyl ester }\end{array}$ & 57.05 \\
\hline 24 & 39.581 & 488780 & 0.89 & 215690 & 1.13 & $\begin{array}{l}\text { 4,4'-((p- } \\
\text { Phenylene)diisopropylidene)diphenol }\end{array}$ & 331.25 \\
\hline \multirow[t]{2}{*}{25} & 44.258 & 3857205 & 7.03 & 417042 & 2.18 & $\begin{array}{l}\text { 2-tert-Butyl-4,6-bis(3,5-di-tert-butyl-4- } \\
\text { hydroxybenzyl)phenol }\end{array}$ & 57.05 \\
\hline & & 54849242 & 100.00 & 19160987 & 100.00 & & \\
\hline
\end{tabular}


Table 3

Inhibition of mycelial growth and conidia germination by volatile organic compounds identified through GC-MS analysis and procured in pure form

\begin{tabular}{|c|c|c|}
\hline Metabolites & $\begin{array}{l}\text { Procured } \\
\text { compounds } \\
\text { (Sigma } \\
\text { Aldrich) }\end{array}$ & $\begin{array}{l}\text { Inhibition of } \\
\text { mycelia and conidial germination by metabolite } \\
\text { from } B \text {. safensis }\end{array}$ \\
\hline Nonadecane & Yes & No \\
\hline Phenol, 2,4-bis (1,1-dimethylethyl)- & Yes & Yes (12.8 mm) \\
\hline Docosane & Yes & No \\
\hline Octadecane & Yes & No \\
\hline 3-hexadecanol & Yes & Yes (10.8 mm) \\
\hline 1-proline, n-valeryl, heptadecyl ester & Yes & No \\
\hline Isopropyl tetradeconoate & Yes & No \\
\hline $\begin{array}{l}\text { Pyrrolo[1,2-a]pyrazine-1,4-dione, hexahydro-3-(2- } \\
\text { methylpropyl)-- }\end{array}$ & Yes & Yes $(9.6 \mathrm{~mm})$ \\
\hline Heptadecance & Yes & No \\
\hline $\begin{array}{l}\text { 7,9-Di-tert-butyl-1-oxaspiro(4,5)deca-6,9-diene-2,8- } \\
\text { dione }\end{array}$ & Yes & No \\
\hline Eicosane & Yes & No \\
\hline $\begin{array}{l}\text { 5,10-Diethoxy-2,3,7,8-tetrahydro- } 1 \mathrm{H}, 6 \mathrm{H} \text { - } \\
\text { dipyrrolo[1,2-a:1',2'-d]pyrazine }\end{array}$ & Yes & Yes $(8.5 \mathrm{~mm})$ \\
\hline 3-ethyl-3-undecanol \# & Yes & No \\
\hline 1,2-benzenedicarboxylic acid, ditridecyl ester & Yes & No \\
\hline Hexadecanoic acid & Yes & Yes $(8.9 \mathrm{~mm})$ \\
\hline Cyclohexanol, 1-butyl- & Yes & No \\
\hline Dotriacontane & Yes & No \\
\hline Tetratetracontane & Yes & No \\
\hline Hexacosyl acetate & Yes & No \\
\hline Hexatriacontane & Yes & No \\
\hline 1,3,5-trisilacyclohexane & Yes & No \\
\hline D-Ribose, 2-deoxy-bis(thioheptyl)-dithioacetal & Yes & No \\
\hline $\begin{array}{l}\text { Hexadecanoic acid, 2-hydroxy-1- } \\
\text { (hydroxymethyl)ethyl ester }\end{array}$ & Yes & No \\
\hline 4,4'-((p-Phenylene) diisopropylidene) diphenol & Yes & No \\
\hline $\begin{array}{l}\text { 2-tert-Butyl-4,6-bis(3,5-di-tert-butyl-4- } \\
\text { hydroxybenzyl)phenol }\end{array}$ & Yes & No \\
\hline
\end{tabular}


Each treatment had five replications and all the experiments were performed in triplicates. Data were analyzed using means and using standard deviation as per Gomez and Gomez (1984).

\section{Results And Discussion}

\subsection{Biocontrol activity}

B. safensis STJP showed biocontrol activity against $A$. alternata in-vitro conditions as confirmed by rapid screening and dual culture methods and the zone of inhibition was $14.8 \pm 1.34 \mathrm{~mm}$ (Fig. 1) and percentage inhibition of $86.24 \pm 2.12 \%$. Bacillus spp. are well known to be safe microorganisms for application in agriculture, holding incredible abilities for synthesizing a wide range of plant beneficial metabolites (Lateef et al. 2015; Prakash and Arora 2019). This genera has potential abilities for improving plant growth and productivity either by direct action such as phytohormones production, solubilization of phosphate, zinc, potassium, and production of siderophore or by controlling phytopathogens (by production of antibiotics, HCN, siderophores and lytic enzymes such as chitinases, glucanases) even under stress conditions (Kapetanakou and Skandamis 2016; Prakash and Arora 2019). The principal mechanisms of phytopathogen control include production of volatile or non-volatile extracellular or intracellular metabolites (Roy et al. 2018). However, there are very few studies available on $B$. safensis as a biocontrol agent against phytopathogen(s). These reports are mainly available on growth inhibition of $B$. safensis against phytopathogens including $A$. alternata by dual culture method, mechanisms till now not be investigated. Some researchers have reported that $B$. safensis produces metabolites such as growth regulators, hormones, lipopeptides, bacilomycins, fengycins, surfactins and other bioactive compounds and their roles have been considered mainly in plant growth and productivity (Lateef et al. 2015; Van Lenteren et al. 2018). Apart from agriculture sector, secondary metabolites from Bacillus spp. are being used in several other industries (pharmaceutical, food, and dairy) (Srikhong et al. 2018). However, useful metabolites from this very diverse genus and in particular from non-pathogenic species such as $B$. safensis can turn out to be very important for managing phytopathogens and organic agriculture production. These metabolites can also be used for development of novel bioformulations which are far more efficient and reliable (Arora and Mishra 2016).

B. safensis STJP was found to be inhibitor of $A$. alternata, causal agent of several diseases in diverse crops (Shafi et al. 2017). The bacterium produced volatile organic compounds and inhibited mycelial growth, and conidia formation of $A$. alternata. Mycelia and conidia of the fungus (taken from seal plate experiment inverted over NA with bacterial growth) failed to germinate, when plated on fresh PDA plate. Overall, STJP was found to be an effective bacterium for volatile compounds production. Abdelmoteleb et al. (2017) observed that Bacillus sp. considerably reduced the growth of $A$. alternata by production of volatile compounds. However, biocontrol potential by $B$. safensis STJP against $A$. alternata ( $86 \%$ ) was found to be better than the earlier reported isolates of Bacillus spp. against phytopathogens including $A$. alternata (60\%), Macrophomina phaseolina (50\%), and Fusarium oxysporum f.sp. cubense (Foc) (79\%) (Pane et al. 2015; Torres et al. 2016; Abdelmoteleb et al. 2017; Bubici et al. 2019)

\subsection{Extracellular or intracellular metabolites production}

$B$. safensis STJP inhibited mycelia growth of $A$. alternata as confirmed by inhibition zone when supernatant was poured, whereas no inhibition zone was observed around the well in which pellet was added. This confirmed that the isolate STJP produced extracellular metabolites which were involved in inhibition of phytopathogen. Further, these extracellular metabolites were found to be volatile in nature as confirmed by seal plate method (Khare and Arora 2011; Islam et al. 2018). Volatile compounds can be far more effective in soil because these can transcend through the layers and soil aggregates and inhibit the phytopathogens hiding in such habitats (Gao et al. 2018). The extracellular metabolites that are secreted by bacterial cells also known as exometabolome are very effective AVOC against fungal phytopathogens including $A$. alternata as compare to intracellular metabolites as reported previously as well (Pinu et al. 2017; Celik et al. 2020).

\subsection{Scanning electron microscope (SEM) analysis}


For SEM analysis, fungal mycelium was taken from dual culture plate in which $B$. safensis STJP inhibited the growth of $A$. alternata. Fungal mycelia of $A$. alternata were also taken from control plate. From the control plate, straight large catenate conidia chains with transverse septa of $A$. alternata were observed (Fig. 3a), whereas from bacterial treated (dual) plate, the destruction, and ruptured hyphae of fungus could be seen (Fig. 3b). Through SEM images it was confirmed that STJP showed strong antagonistic activity against $A$. alternata. On the basis of SEM analysis, it was proved that volatile nature of antifungal compounds was able to prevent conidia germination of $A$. alternata. Volatile compounds produced by $B$. safensis STJP as soil amendments, foliar, or root applications can be used for the control of $A$. alternata. SEM observations suggested that the mycelia of $A$. alternata was deformed, ruptured and disintegrated. In the presence of AVOC, reduced apical growth, cell disruption and irregular distortions in the phytopathogen Aspergillus flavus with reduction in the thickness of mycelium and conidia were observed by Horak et al. (2019) and Muhialdin et al. (2020).

\subsection{Thin layer chromatography (TLC)}

Crude antifungal metabolites obtained after extraction and evaporation of the solvent reached maxium at $7.5 \mathrm{~cm}$ with a retention time of $45 \mathrm{~min}$. On the TLC plate, three major bands were detected under ultraviolet (UV) light (254 nm) in order of decreasing $\operatorname{Rf}$ values $(0.86,0.72,0.14)$ (figure not shown). TLC is a simple, rapid, and economical method of separation, and tentative identification of metabolites. The Rf values $(0.86,0.72,0.14)$ indicate the presence of at least three types of compounds in the extract. Interpretation of results showed aliphatic, aromatic, and phenolic compounds (Rajivgandhi et al. 2019; Celik et al. 2020). However, on the basis of Rf value compounds or their functional groups cannot be identified. Hence further identification of bacterial metabolites was done by FT-IR and GC-MS.

\subsection{Fourier transform-infrared spectroscopy (FT-IR)}

FT-IR spectrum was obtained of the metabolites (dried extract of the supernatant) from B. safensis STJP (Fig. 4). The absorption peaks of the FT-IR spectrum were examined as per Griffith (1996). The absorption peak at $3610.0-3355.4 \mathrm{~cm}^{-1}$ indicated the $-\mathrm{OH}$ group (-OH stretching) with strong intensity corresponded to the existence of alcohol, phenol, and carboxylic acid present in the metabolite sample (Fig. 4). Absorbance peak at $3406.5 \mathrm{~cm}^{-1}$ is attributed to $-0-\mathrm{H}$ stretching corresponded to the presence of carboxylic and phenolic compounds. The absorbance peak $1620.8-1434 \mathrm{~cm}^{-1}$ indicated the $\mathrm{C}$-C stretching resembling the presence of aromatic compounds such as benzene, phenol, and toluene, and absorbance peak $1115.6 \mathrm{~cm}^{-1}$ indicated the alkyl halide and peak $800.7-662.2 \mathrm{~cm}^{-1}$ showed the presence of aliphatic compounds such as alkane or alkene. The absorbance peak at $601.1 \mathrm{~cm}^{-1}$ attributed to alkyl halide and another peak $465.2 \mathrm{~cm}^{-1} \mathrm{showed}$ the alkane group. Overall, the absorbance spectrum of bacterial metabolite from $B$. safensis STJP showed the presence of alcohol, alkane, phenol, alkyl halide, and aromatic ring. Puškárová et al. (2017) reported that aliphatic and aromatic compounds produced by Bacillus spp. were more effective in growth inhibition of A. alternate. However, Wang et al. (2018) suggested that alcohol and phenolic compounds were also found to be efficient in early and post-harvest leaf spot disease control, by A. alternata.

\subsection{GC-MS analysis and examination of antifungal activity of volatile organic compounds}

The GC-MS analysis of chloroform + ethyl acetate + DCM extract revealed the presence of various organic compounds, fatty acid, alcohol, phenol, and other aliphatic compounds at different RT as identified by using NIST mass spectral library (Fig. 5). The major peaks were detected at RT 21.439, 25.191, 27.783, 29.374, 29.765, 31.536, 27.273, 32.263, 37.481 and 44.258 which corresponded to the presence of phenol, 2,4-bis(1,1-dimethylethyl, pyrrolo[1,2-a]pyrazine-1,4-dione, hexahydro3-(2-methylpropyl)-, 5,10-diethoxy-2,3,7,8-tetrahydro-1h,6h-dipyrrolo[1,2-a:1',2'-d]pyrazine, docosane, hexadecanoic acid, cyclohexanol, 1-butyl-, l-proline, n-valeryl-, heptadecyl ester, dotriacontane, d-Ribose, 2-deoxy-bis(thioheptyl)-dithioacetal, and 2-tert-Butyl-4,6-bis(3,5-di-tert-butyl-4-hydroxybenzyl)phenol (Table 2), respectively, based on matching with NIST database. However, all compounds detected at major RT peaks (Table 3) did not play important roles in the antagonistic activity against $A$. alternata (Nicolaou et al. 2011; Siddharth and Vittal 2018). The volatile compounds found to be produced by 
strain B. safensis STJP in the present study, viz., docosane, hexadecanoic acid, cyclohexanol, 1-butyl-, I-proline, n-valeryl-, heptadecyl ester, dotriacontane, d-Ribose, 2-deoxy-bis(thioheptyl)-dithioacetal, and 2-tert-Butyl-4,6-bis(3,5-di-tert-butyl-4hydroxybenzyl)phenol) have been identified to be produced by Bacillus spp. and Pseudomonas spp. and were reported to show antimicrobial, antioxidant, and medicinal properties (Nicolaou et al. 2011; Oda et al. 2017; Jishma et al. 2017; Siddharth and Vittal 2018).

Different minor peaks at RT 21.038, 27.006, 27.085, 27.396, 28.725, 28.817, 28.906, 29.557, 29.614, 32.895, 33.549, 35.898, $37.239,37.743$, and 39.581 resembled to the presence of nonadecane, octadecane, 3-hexadecanol, isopropyl tetradecanoate, heptadecane, 7,9-di-tert-butyl-1-oxaspiro(4,5)deca-6,9-diene-2,8-dione, eicosane, 3-ethyl-3-undecanol, 1,2benzenedicarboxylic acid, ditridecyl ester, tetratetracontane, hexacosyl acetate, hexatriacontane, and 1,3,5trisilacyclohexane (Table 2), respectively. However, in this study, we did not observe inhibition of fungal pathogen from the above compounds except 3-hexadecanol. The compounds nonadecane and octadecane were observed in bacterial metabolite sample of GC-MS, but their function as antifungal compounds or in biological systems is not reported. Hence, it might be possible that these compounds have come from preparation or running samples.

Out of a total of 25 compounds which were identified by GC-MS (produced by B. safensis STJP), 20 synthetic chemical counterparts (based on availability) were purchased from Sigma Aldrich, USA. Among them only 5 compounds (phenol, 2,4bis (1,1-dimethylethyl)-, 3-hexadecanol, pyrrolo[1,2-a]pyrazine-1,4-dione, hexahydro-3-(2-methylpropyl)-, 5,10-diethoxy-2,3,7,8tetrahydro-1 H,6H-dipyrrolo[1,2-a:1',2'-d]pyrazine, and hexadecanoic acid) in pure form (Sigma Aldrich) inhibited the growth of mycelium and conidia germination completely by well plate method at tested volume of $100 \mu \mathrm{l}$ (Table 3). Mycelia or conidia of fungus from the antifungal test, when re-plated on the fresh Petri plates, failed to grow indicating fungicidal property of volatile compounds.

Phenol, 2, 4-bis(1,1-dimethylethyl), a member of the class of phenol carrying two tert-butyl substituents at positions 2 and 4 and already reported as a bacterial metabolite, is known to play an important role in biocontrol activity of several phytopathogens (Dharni et al. 2014; Rice et al. 2019). Phenol 2, 4-bis(1,1-dimethylethyl), produced by B. safensis STJP in the present study, inhibited the growth of $A$. alternata and is important component that delayed spore formation and conidia germination at $100 \mu \mathrm{l}$. Another bacterial metabolite, 3-hexadecanol was detected and their roles are recorded in several industries such as pharmaceuticals, cosmetics, perfumery, detergents and emulsifier (Lou et al. 2013). It is also a type of pesticide but not yet approved by any government agencies and could be involved in the enhancement of plant's immune system as well (Lou et al. 2013). Pyrazine is a heterocyclic compound and its derivatives such as pyrrolo[1,2-a]pyrazine-1,4dione, and 5,10-diethoxy-2,3,7,8-tetrahydro-1H,6H-dipyrrolo[1,2-a:1',2'-d]pyrazine were identified as strong antifungal metabolites against phytopathogens such as Botrytis cinerea, Puccinia recondite, and Rhizoctonia solani and useful for prevention against fungal diseases in plants (Oda et al. 2017). The chemical nature of the organic compounds appears to determine their antifungal property. Pyrrole (5,10-diethoxy-2,3,7,8-tetrahydro-1H,6H-dipyrrolo[1,2-a:1',2'-d]pyrazine) and ketone (pyrrolo[1,2-a]pyrazine-1,4-dione) were more effective than alcohols in the inhibition of growth of $A$. alternata (Lou et al. 2013). Bacterial volatile compounds also promote the growth of plants. Pyrrolo[1,2-a]pyrazine-1,4-dione is reported to enhance the growth of Vigna radiata seedlings and also recorded a potent inhibitory effect on bacterial pathogen (Streptococcus aureus) and fungal pathogen (Jishma et al. 2017). However, fungal response to rhizobacterial volatiles seems to be environment, species and age-specific. Further, hexadecanoic acid detected in crude metabolite extract, showed antifungal activity against several fungal pathogens including Alternaria (Lou et al. 2013). Apart from these metabolites (phenol, 2,4-bis (1,1-dimethylethyl)-, 3-hexadecanol, pyrrolo(1,2-a)pyrazine-1,4-dione, and hexadecanoic acid), another metabolite 5,10-diethoxy-2,3,7,8-tetrahydro-1H,6H-dipyrrolo[1,2-a:1',2'-d]pyrazine, whose role has not been reported earlier in inhibition of recorded in the inhibition of $A$. alternata before. Overall results of the present study suggested that five AVOC produced by $B$. safensis STJP showed strong biocontrol activity against $A$. alternata and this is the first report on the growth inhibition of $A$. alternata by $B$. safensis. It is also for the first time that AVOC (phenol, 2,4-bis (1,1-dimethylethyl)-, 3hexadecanol, pyrrolo(1,2-a)pyrazine-1,4-dione, and hexadecanoic acid, 5,10-diethoxy-2,3,7,8-tetrahydro-1H,6H-dipyrrolo[1,2a:1',2'-d]pyrazine) were detected to be produced by $B$. safensis. However, other compounds produced by $B$. safensis STJP 
might be playing roles in other activities such as plant microbe interactions or development of plant immune response and required to be investigated further.

\section{Conclusion}

It can be concluded that $B$. safensis can be an eco-friendly tool for promoting plant growth by using as a biocontrol agent against fungal phytopathogens. $B$. safensis produced a bouquet of antifungal volatile compounds against $A$. alternata. The antifungal compounds were mainly volatile in nature. The exploitation of $B$. safensis as a biopesticide would be a good option in for production of healthy food, reducing health problems related with chemical pesticides, and sustainable crop and agro-industry. The variety of extracellular metabolites produced by $B$. safensis may be involved in several other roles related to plant-microbe interactions which need to be explored further.

\section{Declarations}

\section{Acknowledgements:}

The authors were highly obliged to Vice chancellor of BBA University (A Central University) for providing the vital facility for all experimental work. Authors are also grateful to University Science Instrument Centre (USIC) for providing SEM and FT-IR facility. Authors also acknowledged to Central Drug Research Institute (CDRI), Lucknow, Uttar Pradesh, India for GC-MS analysis.

Author Contributions: Conceptualization, JP and NKA; methodology, resources, J.P. writing-original draft preparation, NKA review and editing, and supervision. All authors have read and agreed to the published of the manuscript article.

Source of funding: This research did not receive any financial support from funding agencies in the public, commercial, or not-for-profit sectors.

Conflict of interest: Authors declare that there is no conflict of interest in this research article

Ethical statement: This research article does not contain any experiments/studies with animals performed by any of the authors.

\section{References}

1. Abdelmoteleb A, Troncoso-Rojas R, Gonzalez-Soto T, González-Mendoza D (2017) Antifungical activity of autochthonous Bacillus subtilis isolated from Prosopis juliflora against phytopathogenic fungi. Mycobiolog 45(4):385391

2. Alori ET, Babalola $O O$ (2018) Microbial inoculants for improving crop quality and human health in Africa. Front Microbiol 9:2210-2213

3. Arora NK, Kang SC, Maheshwari DK (2001) Isolation of siderophore-producing strains of Rhizobium meliloti and their biocontrol potential against Macrophomina phaseolina that causes charcoal rot of groundnut. Cur Sci 673-677

4. Arora NK, Mishra J (2016) Prospecting the roles of metabolites and additives in future bioformulations for sustainable agriculture. Appl Soil Ecol 107:405-407

5. Borriss R (2020) Phytostimulation and biocontrol by the plant-associated Bacillus amyloliquefaciens FZB42: an update. In Phyto-Microbiome in Stress Regulation Springer, Singapore 1:1-20

6. Bubici G, Kaushal M, Prigigallo MI, Gómez-Lama Cabanás C, Mercado-Blanco J (2019) Biological control agents against Fusarium wilt of banana. Front Microbiol 10:616 
7. Celik S, Ozkok F, Ozel AE, Müge Sahin Y, Akyuz S, Sigirci BD, Kahraman BB, Darici H, Karaoz E (2020) Synthesis, FT-IR and NMR characterization, antimicrobial activity, cytotoxicity and DNA docking analysis of a new anthraquinone derivate compound. J Biomol Str Dyn 38(3):756-770

8. Chakraborty S, Newton AC (2011) Climate change, plant diseases and food security: an overview. Plant Pathol 60(1):214

9. Danial AM, Medina A, Sulyok M, Magan N (2020) Efficacy of metabolites of a Streptomyces strain (AS1) to control growth and mycotoxin production by Penicillium verrucosum, Fusarium verticillioides and Aspergillus fumigatus in culture. Mycotoxin Res 36: 225-234

10. Dharni S, Maurya A, Samad A, Srivastava SK, Sharma A, Patra DD (2014) Purification, characterization, and in vitro activity of 2, 4-di-tert-butylphenol from Pseudomonas monteilii PsF84: conformational and molecular docking studies. J Agri Food Chem 62(26):138-6146

11. FAO (2012) Agriculture Organization of the United Nations. FAO statistical yearbook

12. Fernando WD, Ramarathnam R, Krishnamoorthy AS, Savchuk SC (2005) Identification and use of potential bacterial organic antifungal volatiles in biocontrol. Soil Biol Biochem 37(5): 955-964

13. Gao H, Li P, Xu X, Zeng Q, Guan W (2018) Research on volatile organic compounds from Bacillus subtilis CF-3: biocontrol effects on fruit fungal pathogens and dynamic changes during fermentation. Front Microbiol. 9:456-468

14. Gocan S (2002) Stationary phases for thin-layer chromatography. J Chromat Sci 40(10):538-549

15. Gomez KA, Gomez AA (1984) Statistical procedures for agricultural research. John Wiley and Sons, New York Feb 17

16. Griffith DW (1996) Synthetic calibration and quantitative analysis of gas-phase FT-IR spectra. Appl Spect 50(1):59-70

17. Harman GE, Uphoff N (2019) Symbiotic root-endophytic soil microbes improve crop productivity and provide environmental benefits. Scientifica 19:1-25.

18. Hennequin LF, Allen J, Breed J, Curwen J, Fennell M, Green TP (2006) Lambert-van der Brempt, C.; Morgentin, R.; Norman, R, A.; Olivier, A.; Otterbein, L. N-(5-Chloro-1, 3-benzodioxol-4-yl)-7-[2-(4-methylpiperazin-1-yl) ethoxy]-5(tetrahydro-2 H-pyran-4-yloxy) quinazolin-4-amine, a novel, highly selective, orally available, dual-specific c-Src/Abl kinase inhibitor. J Med Chem 49(22):6465-6488

19. Horak I, Engelbrecht G, van Rensburg PJ, Claassens S (2019) Microbial metabolomics: essential definitions and the importance of cultivation conditions for utilizing Bacillus species as bionematicides. J Appl Microbiol 127(2):326-343

20. Islam MA, Nain Z, Alam MK, Banu NA, Islam MR (2018) In vitro study of biocontrol potential of rhizospheric Pseudomonas aeruginosa against Fusarium oxysporum f. sp. Cucumerinum. Egyptian J Biolog Pest Cont 28(1):90-101

21. Jishma P, Hussain N, Chellappan R, Rajendran R, Mathew J, Radhakrishnan EK (2017) Strain-specific variation in plant growth promoting volatile organic compounds production by five different Pseudomonas spp. as confirmed by response of Vigna radiata seedlings. J App Microbiol 123(1):204-216

22. Kai M (2020) Diversity and distribution of volatile secondary metabolites throughout Bacillus subtilis isolates. Front Microbiol 11:549-559

23. Kaminskyj SG, Dahms TE (2008) High spatial resolution surface imaging and analysis of fungal cells using SEM and AFM. Micron 39(4):349-361

24. Kapetanakou AE, Skandamis PN (2016) Applications of active packaging for increasing microbial stability in foods: natural volatile antimicrobial compounds. Cur Opi Food Sci 12:1-12

25. Kaspar F, Neubauer P, Gimpel M (2019) Bioactive Secondary Metabolites from Bacillus subtilis: A Comprehensive Review. J Natur Prod 82(7):2038-2053

26. Kersten PJ, Kirk TK (1987) Involvement of a new enzyme, glyoxal oxidase, in extracellular $\mathrm{H}_{2} \mathrm{O}_{2}$ production by Phanerochaete chrysosporium. J Bacteriol 169(5):2195-2201 
27. Khare E, Arora NK (2011) Dual activity of pyocyanin from Pseudomonas aeruginosa-antibiotic against phytopathogen and signal molecule for biofilm development by rhizobia. Canadian J Microbiol 57(9):708-713

28. Lateef A, Adelere IA, Gueguim-Kana EB (2015) The biology and potential biotechnological applications of Bacillus safensis. Biologia 70:411-429

29. Lou J, Fu L, Peng Y, Zhou L (2013) Metabolites from Alternaria fungi and their bioactivities. Molecules 18(5):5891-5935

30. Meena M, Swapnil P, Upadhyay RS (2017) Isolation, characterization and toxicological potential of A/ternariamycotoxins (TeA, AOH and AME) in different Alternaria species from various regions of India. Sci Rep 7(1): 1-19 Mishra J, Prakash J, Arora NK (2016) Role of beneficial soil microbes in sustainable agriculture and environmental management. Climate Chang Environ Sustain 4(2):137-149.

31. Muhialdin BJ, Algboory HL, Kadum H, Mohammed NK, Saari N, Hassan Z, Hussin ASM (2020) Antifungal activity determination for the peptides generated by Lactobacillus plantarum TE10 against Aspergillus flavus in maize seeds. Food Contr 109:106898

32. Müller T, Lentzsch P, Behrendt U, Barkusky D, Müller ME (2019) Pseudomonassimiae effects on the mycotoxin formation by Fusaria and Alternaria in vitro and in a wheat field. Mycotoxin Res. 36(2):147-158

33. Nicolaou KC, Ellery SP, Rivas F, Saye K, Rogers E, Workinger TJ, Schallenberger M, Tawatao R, Montero A, Hessell A (2011) Romesberg, F Synthesis and biological evaluation of 2', 4'-and 3', 4'-bridged nucleoside analogues. Bioorg Med Chem 19(18):5648-5669

34. Nowicki MM, Nowakowska A, Niezgoda (2012) Alternaria black spot of crucifers: symptoms, importance of disease and perspectives of resistance breeding. Veg Crop Res Bulletin 76:5-19

35. Oda M, Furuya T, Morishita Y, Matsuzaki Y, Hasebe M, Kuroki N (2017) Synthesis and biological activity of a novel fungicide, pyraziflumid. J Pest Sci 17:17-041

36. Pane C, Zaccardelli M (2015) Evaluation of Bacillus strains isolated from solanaceous phylloplane for biocontrol of Alternaria early blight of tomato. Biolog Cont 84:11-18

37. Pinu FR, Villas-Boas SG, Aggio R (2017) Analysis of intracellular metabolites from microorganisms: quenching and extraction protocols. Metabolites 7(4):53-65

38. Prakash J, Arora NK (2019) Phosphate-solubilizing Bacillus sp. enhances growth, phosphorus uptake and oil yield of Mentha arvensis L. 3 Biotech 9(4):115-126

39. Prakash J, Arora NK (2020) Development of Bacillus safensis-based liquid bioformulation to augment growth, stevioside content, and nutrient uptake in Stevia rebaudiana. World J Microbiol Biotechnol 36(1):1-13.

40. Puškárová A, Bučková M, Kraková L, Pangallo D, Kozics K (2017) The antibacterial and antifungal activity of six essential oils and their cyto/genotoxicity to human HEL 12469 cells. Sci Rep7(1):1-11

41. Rajivgandhi G, Ramachandran G, Maruthupandy M, Vaseeharan B, Manoharan N (2019) Molecular identification and structural characterization of marine endophytic actinomycetes Nocardiopsis sp. GRG 2 (KT 235641) and its antibacterial efficacy against isolated ESBL producing bacteria. Microbial Path 126:138-148

42. Reddy KRN, Reddy CS, Muralidharan K (2009) Detection of Aspergillus spp. and aflatoxin B1 in rice in India. Food Microbiol 26(1):27-31

43. Rice S, Maurer DL, Fennell A, Dharmadhikari M, Koziel JA (2019) Evaluation of volatile metabolites emitted in-vivo from cold-hardy grapes during ripening using SPME and GC-MS: A proof-of-concept. Molecules 24(3):536

44. Roy T, Bandopadhyay A, Sonawane PJ, Majumdar S, Mahapatra NR, Alam S, Das N (2018) Bio-effective disease control and plant growth promotion in lentil by two pesticide degrading strains of Bacillus sp. Biolog Cont 127:55-63

45. Schoeman M, Webber J, Dickinson DA (1994) rapid method for screening potential biological control agents of wood decay. Eur J For Pathol 24(3):154-159

46. Shafi J, Tian H, Ji M (2017) Bacillus species as versatile weapons for plant pathogens: a review. Biotechnol Biotechnol Equip 31(3):446-459

Page 14/17 
47. Shumaila S, Khan MR (2016) Biological control of root-rot on mungbean plants incited by Macrophomina phaseolina through microbial antagonists. Plant Pathol J 15(2):27-39

48. Shuping DSS, Eloff JN (2017) The use of plants to protect plants and food against fungal pathogens: A review. African J Trad Compl Alter Med 14(4):120-127

49. Siddharth S, Vittal RR (2018) Evaluation of antimicrobial, enzyme inhibitory, antioxidant and cytotoxic activities of partially purified volatile metabolites of marine Streptomyces sp. S2A. Microorganisms 6(3):72-84

50. Srikhong P, Lertmongkonthum K, Sowanpreecha R, Rerngsamran P (2018) Bacillus sp. strain M10 as a potential biocontrol agent protecting chili pepper and tomato fruits from anthracnose disease caused by Colletotrichum capsici. BioContr 63(6):833-842

51. Stoica RM, Moscovici M, Tomulescu C, Cășărică A, Băbeanu N, Popa O, Kahraman HA (2019) Antimicrobial compounds of the genus Bacillus: A review. Rom Biotechnol Lett 24(6):1111-1119

52. Thomma BP (2003) Alternaria spp. from general saprophyte to specific parasite. Mol Plant Pathol 4(4):225-236

53. Torres MJ, Brandan CP, Petroselli G, Erra-Balsells R, Audisio MC (2016) Antagonistic effects of Bacillus subtilis subsp. subtilis and B. amyloliquefaciens against Macrophomina phaseolina: SEM study of fungal changes and UV-MALDITOF MS analysis of their bioactive compounds. Microbiol Res 182:31-39

54. Van Lenteren JC, Bolckmans K, Köhl J, Ravensberg WJ, Urbaneja A (2018) Biological control using invertebrates and microorganisms: plenty of new opportunities. BioContr 63(1):39-59

55. Wang H, He W, Wang H, Dong F (2018) In situ FT-IR investigation on the reaction mechanism of visible light photocatalytic NO oxidation with defective g-C3N4. Sci. Bulletin. 63(2):117-125

56. Watts N, Amann M, Ayeb-Karlsson S, Belesova K, Bouley T, Boykoff M, Cox PM (2018) The Lancet Countdown on health and climate change: from 25 years of inaction to a global transformation for public health. The Lancet 391(10120):581-630

\section{Figures}

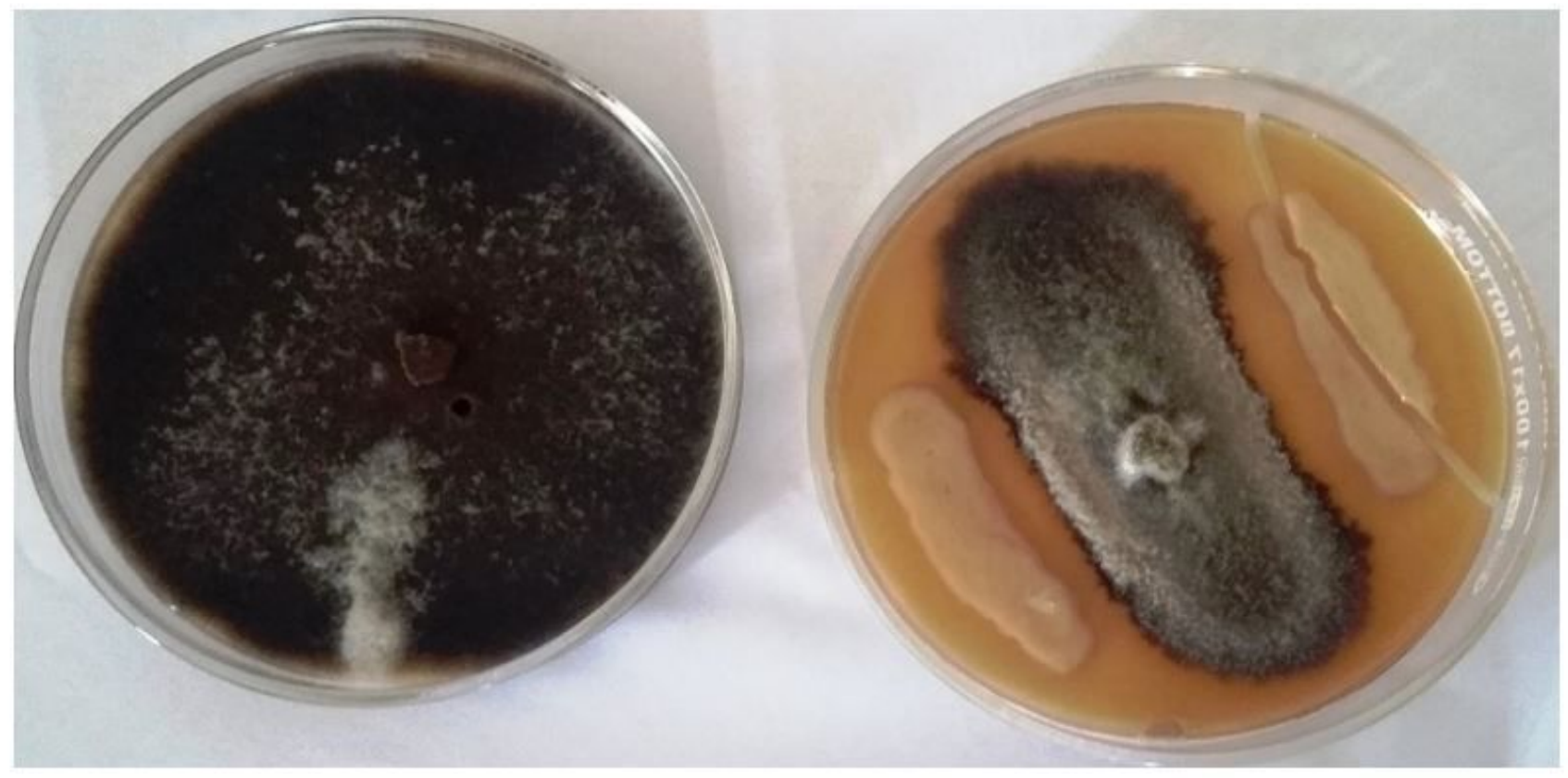




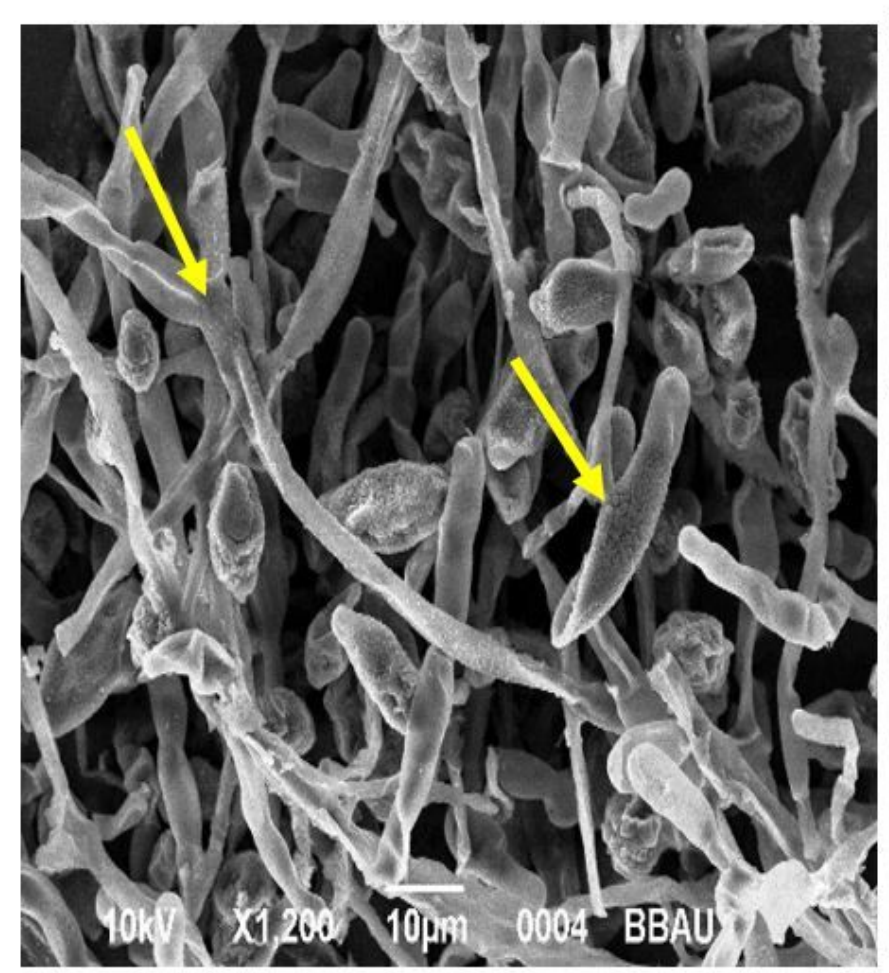

Fig. 2a

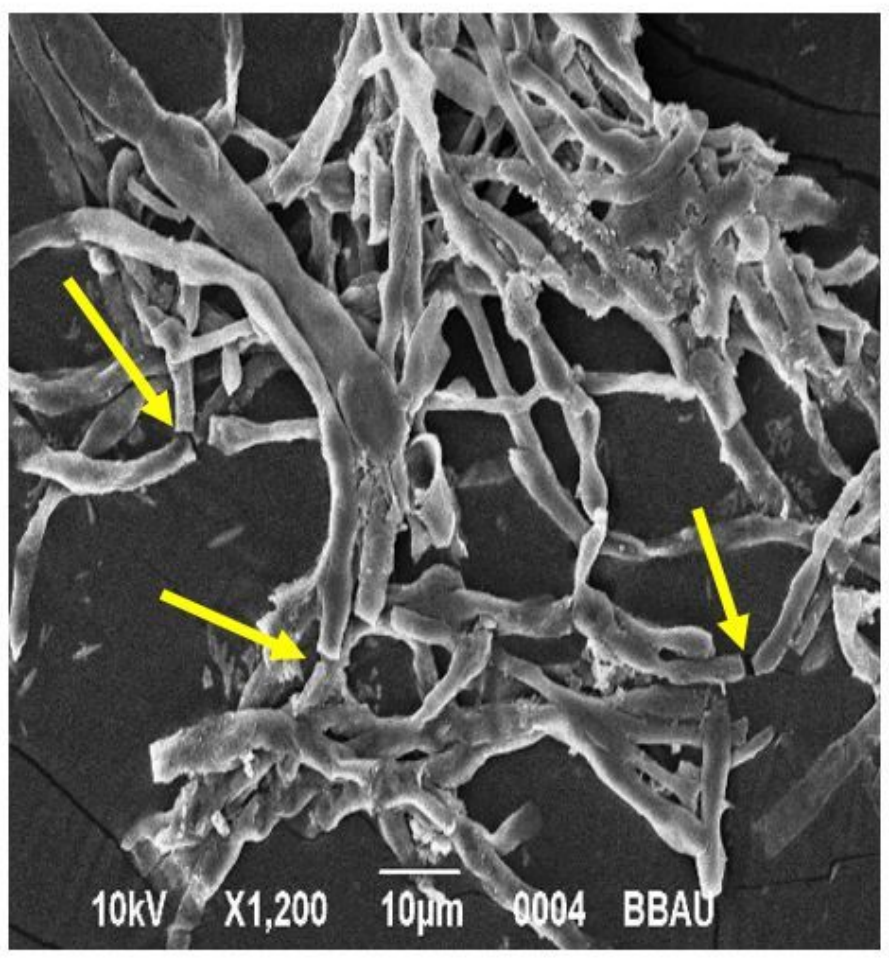

Fig. 2b

Figure 2

a) SEM image of $A$. alternata showing healthy mycelia and conidia (control)

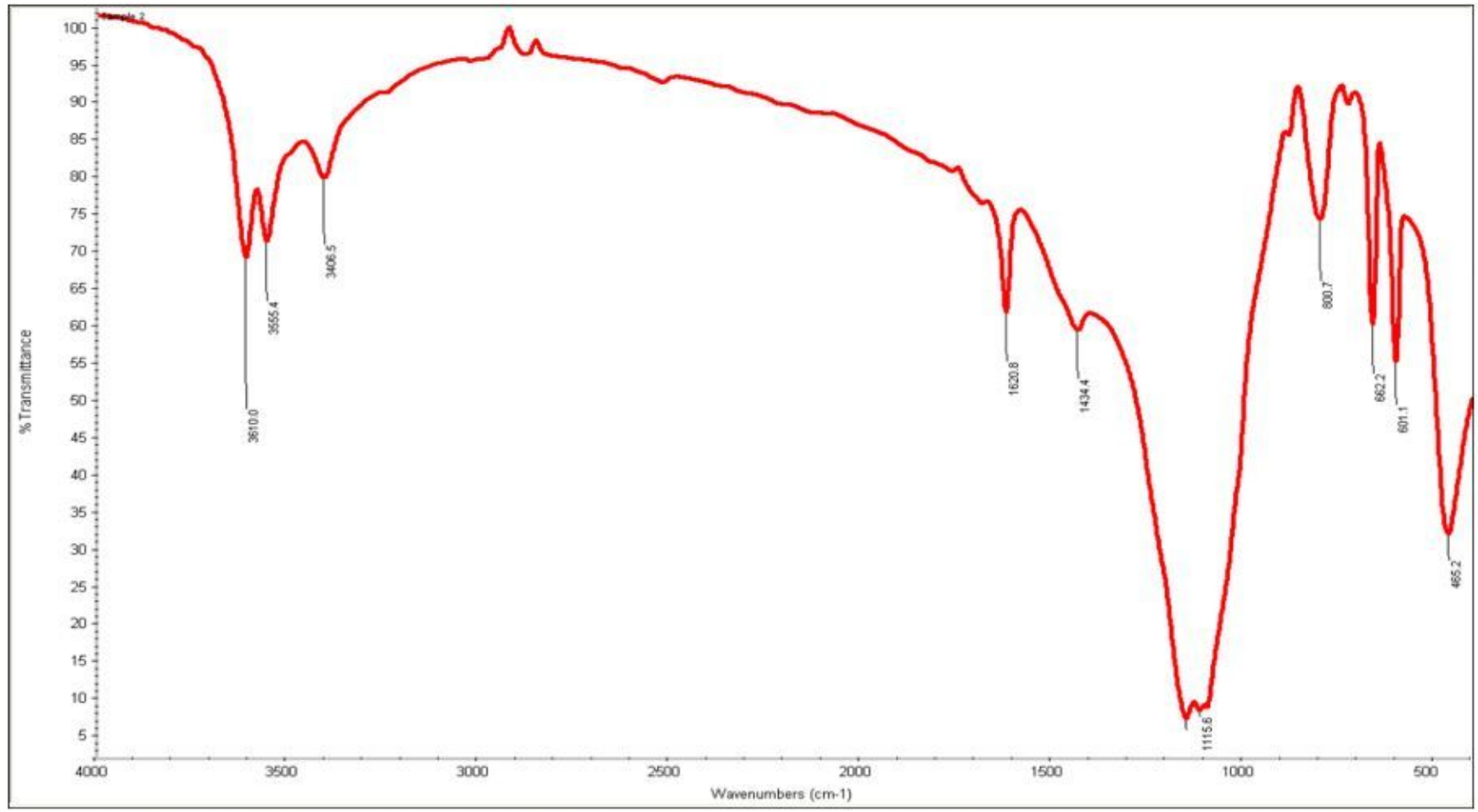




\section{Figure 3}

FT-IR spectra of metabolites sample extracted from bacterial supernatant [peaks showing different frequencies $(\mathrm{cm}-1)$ ]

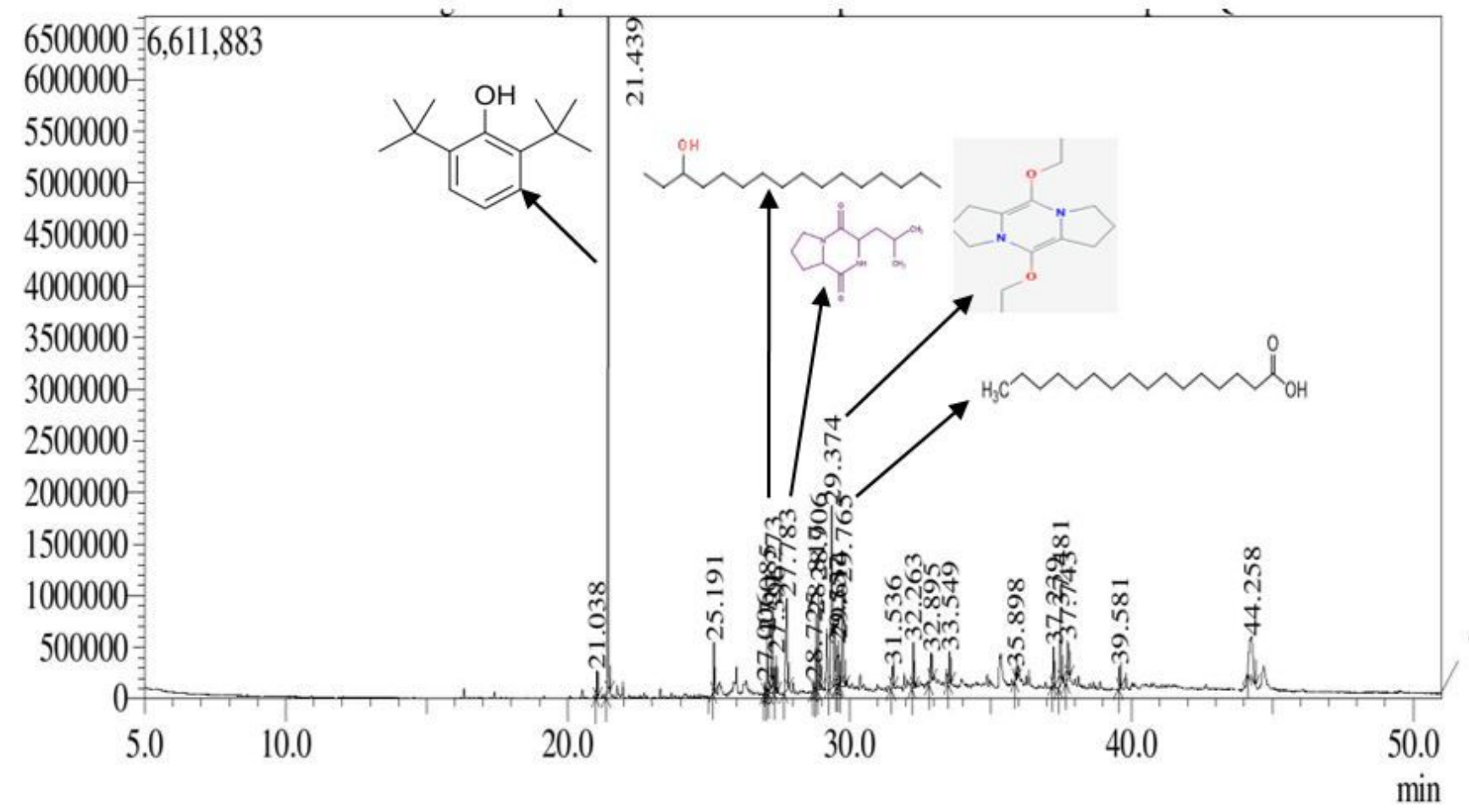

Figure 4

Chromatogram of GC showing peaks of different metabolites derived from extracted bacterial supernatant. Each labeled refers to AVOC: 1) phenol, 2,4-bis (1,1-dimethylethyl)- (RT: 21.439), 2) 3-hexadecanol (RT: 27.085), 3) pyrrolo(1,2-a)pyrazine1,4-dione (RT: 27.783), 4) 5,10-diethoxy-2,3,7,8-tetrahydro-1H,6H-dipyrrolo(1,2-a:1',2'-d)pyrazine (RT: 29.374), and 5) hexadecanoic acid (RT: 29.765) 